\title{
Minimal stress shielding with a Mallory-Head titanium femoral stem with proximal porous coating in total hip arthroplasty Brad Ellison*1, Nicholas A Cheney ${ }^{2}$, Keith R Berend ${ }^{3}$, Adolph V Lombardi Jr ${ }^{3}$ and Thomas H Mallory ${ }^{3}$
}

\author{
Address: ${ }^{1}$ The Ohio State University, Department of Orthopedic Surgery, Columbus, OH, USA, ${ }^{2}$ Ohio University College of Osteopathic Medicine \\ Athens, Ohio, USA and 3Joint Implant Surgeons, Inc, The Ohio State University, New Albany Surgical Hospital, New Albany, Ohio, USA \\ Email: Brad Ellison* - ellysonic@yahoo.com; Nicholas A Cheney - BerendKR@joint-surgeons.com; Keith R Berend - LombardiAV@joint- \\ surgeons.com; Adolph V Lombardi - MalloryTH@joint-surgeons.com; Thomas H Mallory - CheneyNA@joint-surgeons.com \\ * Corresponding author
}

Published: 9 December 2009

Journal of Orthopaedic Surgery and Research 2009, 4:42 doi:10.1 186/1749-799X-4-42

This article is available from: http://www.josr-online.com/content/4/I/42

(C) 2009 Ellison et al; licensee BioMed Central Ltd.

This is an Open Access article distributed under the terms of the Creative Commons Attribution License (http://creativecommons.org/licenses/by/2.0), which permits unrestricted use, distribution, and reproduction in any medium, provided the original work is properly cited.
Received: 18 February 2009

Accepted: 9 December 2009

\begin{abstract}
Background: As longevity of cementless femoral components enters the third decade, concerns arise with long-term effects of fixation mode on femoral bone morphology. We examined the longterm consequences on femoral remodeling following total hip arthroplasty with a porous plasmasprayed tapered titanium stem.
\end{abstract}

Methods: Clinical data and radiographs were reviewed from a single center for 97 randomly selected cases implanted with the Mallory-Head Porous femoral component during primary total hip arthroplasty. Measurements were taken from preoperative and long-term follow-up radiographs averaging 14 years postoperative. Average changes in the proximal, middle and diaphyseal zones were determined.

Results: On anteroposterior radiographs, the proximal cortical thickness was unchanged medially and the lateral zone increased I.3\%. Middle cortical thickness increased $4.3 \%$ medially and $1.2 \%$ laterally. Distal cortical thickness increased $9.6 \%$ medially and $1.9 \%$ laterally. Using the anteroposterior radiographs, canal fill at $100 \mathrm{~mm}$ did not correlate with bony changes at any level (Spearman's rank correlation coefficient of $-0.18,0.05$, and 0.00; $\mathrm{p}$ value $=0.09,0.67,0.97$ ). On lateral radiographs, the proximal cortical thickness increased $1.5 \%$ medially and $0.98 \%$ laterally. Middle cortical thickness increased $2.4 \%$ medially and $1.3 \%$ laterally. Distal cortical thickness increased $3.5 \%$ medially and $2.1 \%$ laterally. From lateral radiographs, canal fill at $100 \mathrm{~mm}$ correlated with bony hypertrophy at the proximal, mid-level, and distal femur (Spearman's rank correlation coefficient of $0.85,0.33$, and 0.28 , respectively; $p$ value $=0.00 \mathrm{I}, 0.016$, and $0.0 \mathrm{I}$, respectively).

Conclusion: Stress shielding is minimized with the Mallory-Head titanium tapered femoral stem with circumferential proximal plasma-sprayed coating in well-fixed and well-functioning total hip arthroplasty. Additionally, the majority of femora demonstrated increased cortical thickness in all zones around the stem prosthesis. Level of Evidence: Therapeutic Level III. 


\section{Introduction}

In accordance with Wolff's law of bone remodeling, the implantation of a hip stem into the medullary canal of the proximal femur results in a change of the strain pattern along the femur. This change may be associated with negative remodeling, termed "stress shielding" [1-6]. Although stress shielding raises concerns of prosthetic loosening and periprosthetic fracture, the long-term consequences of stress shielding have not yet been correlated with adverse effects on implant survival [7].

A flexible metallic substrate, such as titanium, more closely approximates the elastic modulus of cortical bone allowing stress and strain to be transferred more evenly from prosthetic stem to the surrounding proximal femur. Thus, titanium stems minimize disuse atrophy from developing in cortical bone secondary to mechanical offloading when compared with more rigid cobalt-chrome stems [8]. The tapered stem is designed to convert axial forces into radial compressive forces, which favorably transfers load more evenly to the proximal metaphysis limiting the effects of stress [9]. Early porous-coated cementless designs contained extensive porous coating over the entire stem, were designed for diaphyseal fixation, and demonstrated excellent clinical outcomes. However, long-term radiographic signs of stress shielding have been concerning with these stem designs [10-13]. In securing metaphyseal fixation rather than diaphyseal fixation, proximal porous coating may minimize this stress shielding observed with extensively porous-coated stems.

The purpose of the current study is to quantify the location and degree of long-term proximal femoral remodeling around a well-fixed, cementless, tapered, proximally porous-coated femoral component (Figure 1). Additionally, the authors postulate that the canal fill of the femoral stem correlates with positive bony remodeling using this type of stem.

\section{Materials and methods Patient Selection}

Clinical data and radiographs from 192 hips, representing all primary total hip arthroplasties performed between 1987 and 1990 with a cementless tapered titanium femoral stem, were identified from the electronic database at our institution. Immediate postoperative anteroposterior and lateral radiographs following primary total hip arthroplasty were scanned into our office picture archiving and communication system (Stryker, Rutherford, New Jersey). Subsequent follow-up anteroposterior and lateral radiographs, either digital or traditional, were scanned into the picture archiving and communication system. Using the picture archiving and communication system software, a system of standardization allowed comparison of cortical thickness of the proximal femur based on anter-

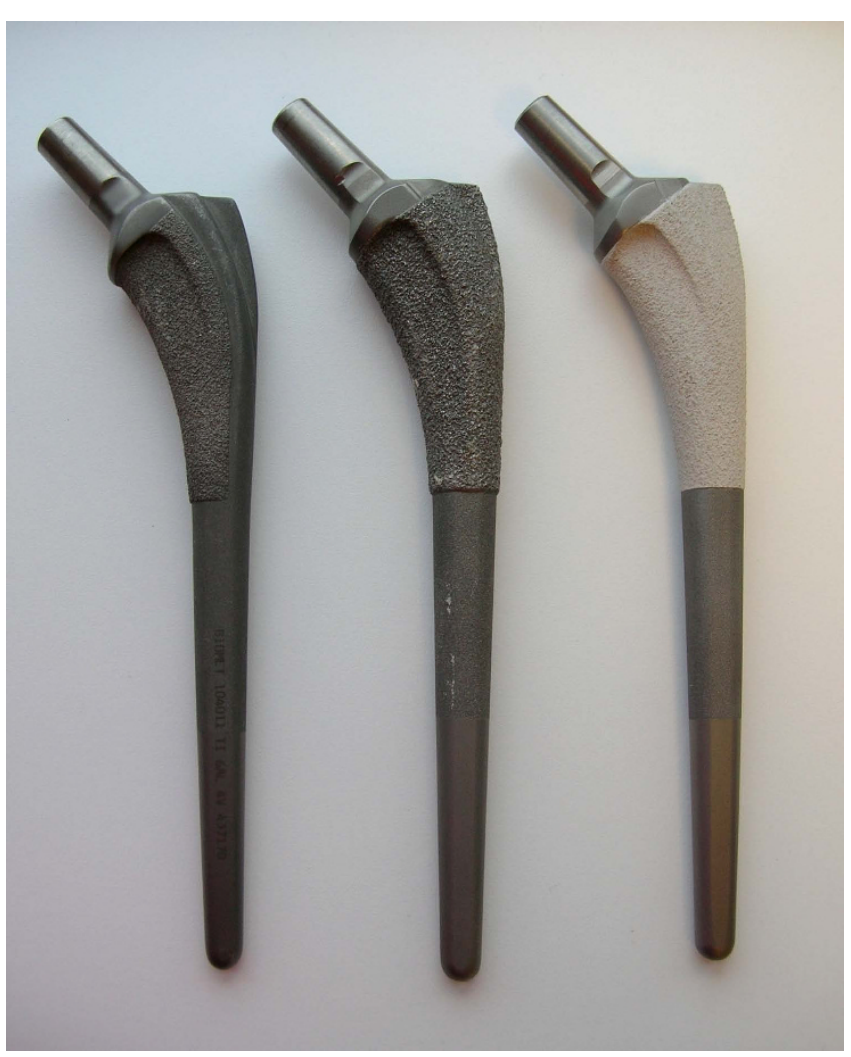

Figure I

The Mallory-Head Porous femoral component (Biomet, Warsaw, Indiana) is a collarless, titanium, tapered device with plasma-spray coating on the distal third, grit blasted on the middle third, and satintextured on the distal third. On the left is shown the component as it was first introduced in August 1984, with the plasma-spray coating covering only $62.5 \%$ of the proximal third, on the medial surfaces only. In the middle is shown the standard component with the plasma-spray coating extended circumferentially as a barrier against particulate debris, beginning in January 1987 and as currently available. On the right is shown the component with the option of hydroxyapatite coating applied over the plasma-spray coating on the proximal third, which was first available in November 1988. In addition, a lateralized offset option became available in March 2000.

oposterior and lateral radiographs from early and late follow-up studies.

For each patient, a certified radiology technician obtained standard AP hip and Lateral hip radiographs in a standardized fashion. The AP hip radiograph was performed in the supine position with the pelvis in the hip and pelvis oriented in the true anterior-to-posterioor projection overlying a film cassette with each hip and lower extremity internally rotated 15 degrees, which aligns the proximal femur parallel with the film cassette. The collimated 
$\mathrm{x}$-ray beam is aimed directly perpendicular to the pelvis, hip and radiograph cassette. The Lauenstein lateral hip radiograph was performed in the supine position with the targeted hip flexed, abducted and slightly externally rotated until the proximal thigh is positioned on top of the film cassette. In a similar fashion to the AP hip radiograph, the x-ray beam is aimed directly perpendicular to the proximal thigh and pelvis. The image displaying the proximal femur and acetabulum is previewed by the radiology technician to ensure proper orientation of the greater trochanter, lesser trocanter and that all aspects of the femoral and acetabular components are appropriately visualized.

Upon review, 97 primary total hip arthroplasty cases had a complete radiographic evaluation, spanning initial preoperative radiographs to a minimum of 10 -year postoperative follow-up. Radiographs which did not provide adequate visualization of each Gruen zone were eliminated [14]. Other radiographs in patients who had undergone acetabular revision in which the resultant femoral head size was unknown (used for picture archiving and communication system calibration) were eliminated. Additionally, radiographs of insufficient quality to be scanned and accurately measured were excluded from measurement. The resultant 97 randomly selected primary total hip arthroplasties were performed at a single institution using a single stem design. Using a blinded radiographic observer trained in the technique of measuring the relative cortical thickness, standardized measurements of the proximal, middle and diaphyseal bone thickness were taken from these radiographs.

\section{Surgical Technique}

All procedures were performed in the lateral decubitus position using the anterolateral abductor splitting approach, as described by Frndak, et al [15]. Implantation involved sequential reaming and broaching to achieve a canal fit at $100 \mathrm{~mm}$ distal to the level of the femoral neck osteotomy. All femora were implanted with the MalloryHead Porous (Biomet, Inc.; Warsaw, IN) femoral component: a straight, tapered, titanium stem with circumferential, titanium, porous-plasma-spray over the proximal one-third. The middle third of the stem is grit blasted and the distal third is matte finished. The design objective of this stem is to preferentially load the proximal femur with gradual diminution of load in a proximal to distal fashion.

\section{Radiographic Measurements}

Using the picture archiving and communication system radiographic standardization, the cortical thickness was measured in all seven Gruen zones [14], including proximal medial and lateral zones, middle medial and lateral zones, distal medial and lateral zones, and the final zone at the distal stem tip (Figure 2). The known diameter of the femoral head was used as a reference for magnification. The initial six-week postoperative radiographs were compared with the most recent radiographs in a side-byside analysis using the picture archiving and communication system, ensuring measurements made for both images were consistently taken from the same level. The thickness in each of these regions was measured to the closest millimeter. Changes in the cortical thickness depicted on the anteroposterior and lateral radiographs were represented as a percentage calculated by subtracting the six-week postoperative cortical thickness from the most recent cortical thickness, then dividing by the sixweek postoperative cortical thickness: [ (most recent cortical thickness minus six-week postoperative follow-up cortical thickness) divided by six-week postoperative followup cortical thickness] multiplied by 100 .

\section{Statistical Methods}

Statistical analysis was performed using StatsDirect (StatsDirect Ltd., United Kingdom). Routine statistical analyses included unpaired student's t-test for parametric variables and Fisher's exact test on counts for dichotomous variables. Analysis of correlation was performed using Spearman's ranked correlation. Significance was defined as a p $<0.05$, power analysis was performed using 80\%, and confidence intervals were calculated at 95\%.

\section{Results}

\section{Patient Demographics \& Data}

Clinical follow-up in this series averaged 15.2 years and radiographic follow-up averaged 14.0 years. The average age at time of implantation was 50 years old (range 22-78 years, standard deviation 11). The distribution of females was $48.5 \%$. The average height of the patients was 67 inches (range 52-78 inches, standard deviation 6). The average weight of the patients was 180 pounds (range 92371 , standard deviation 52). The average size of the femoral stem was $12.0 \mathrm{~mm}$ (range $7-17 \mathrm{~mm}$, standard deviation 2.6).

\section{Changes in Cortical Thickness around the Mallory-Head Porous component from anteroposterior and Lateral radiographs}

With the picture archiving and communication system technique of radiographic standardization, anteroposterior radiographs from the early post-operative period were compared with anteroposterior radiographs taken from the most recent follow-up visit. The cortical thickness was measured in each of the seven Gruen zones and the average change was recorded (Figure 3), followed by identification of the proportion of hips in the study group that demonstrated increased or unchanged thickness in the proximal femur following primary total hip arthroplasty (Figure 4). In the proximal lateral region (Gruen zone 1), 


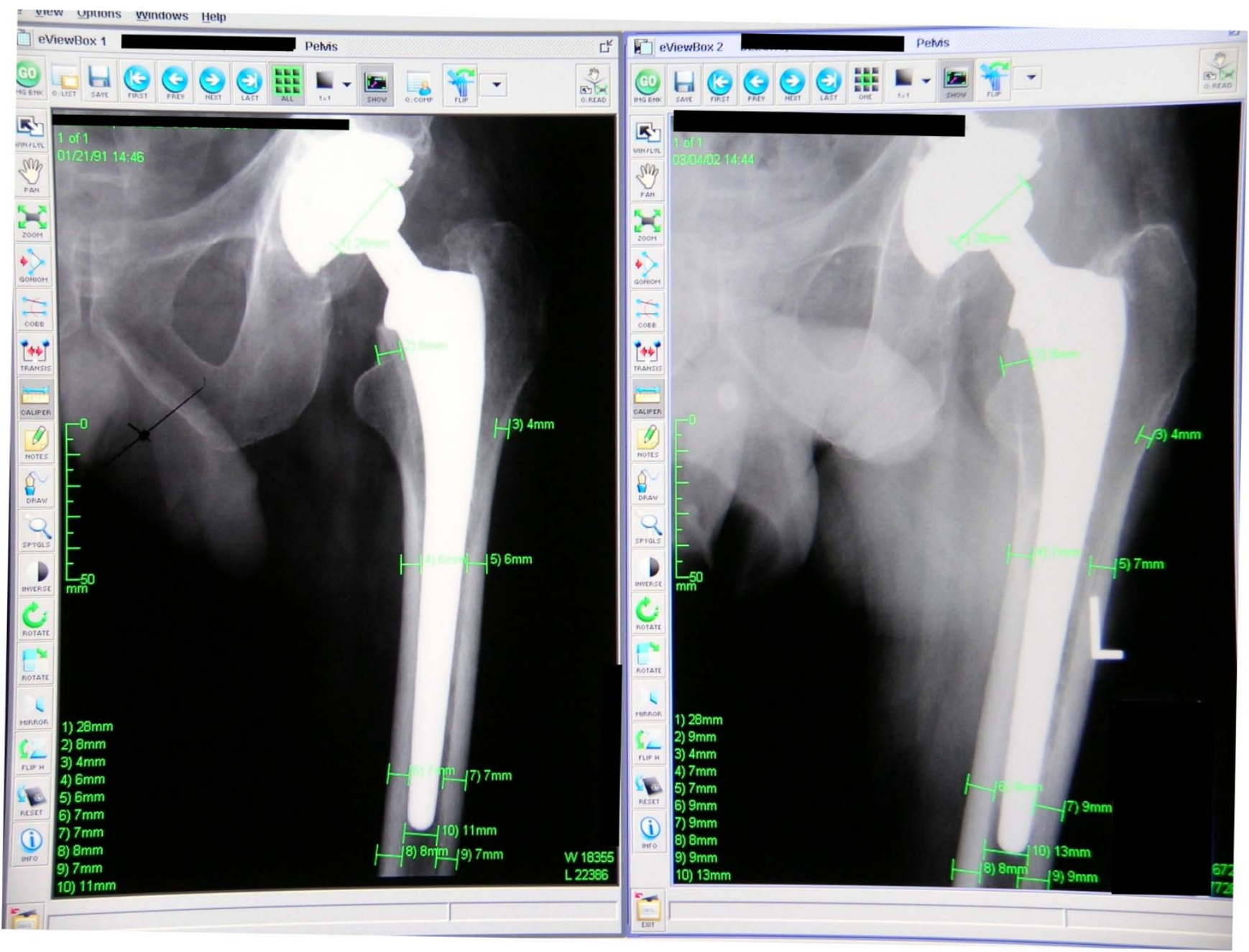

\section{Figure 2}

Image taken from the picture archiving and calibration system, demonstrating the areas measured on the immediate postoperative (left) and most recent anteroposterior radiographs (right), with magnification calibrated from the known diameter of the modular femoral head component.

an average increase of $1.3 \%$ in the cortical thickness was observed with $68.4 \%$ of hips demonstrating increased or unchanged cortical thickness in this zone. In the proximal medial region (Gruen zone 7 ), an average change of $0 \%$ was observed with $63.5 \%$ of hips demonstrating increased or unchanged cortical thickness in this zone. In the middle lateral region (Gruen zone 2), an average increase of $1.2 \%$ in the cortical thickness was observed with $62.4 \%$ of hips demonstrating increased or unchanged cortical thickness in this zone. In the middle medial zone (Gruen zone $6)$, an average increase of $4.3 \%$ in the cortical thickness was observed with $74.0 \%$ of hips demonstrating increased or unchanged cortical thickness. In the distal lateral zone (Gruen zone 3), an average increase of 1.9\% in the cortical thickness was observed with $72.2 \%$ of hips demonstrating increased or unchanged cortical thickness in this zone. In the distal medial zone (Gruen zone 5) the average increase of $9.6 \%$ in the cortical thickness was observed with $78.5 \%$ of hips demonstrating increased or unchanged cortical thickness. In Gruen zone 4, the average increase in the lateral cortex was $11.1 \%$ with $81.1 \%$ of hips demonstrating increased or unchanged cortical thickness and the average increase in the medial cortex was. Additionally, the medial cortex in Gruen zone 4 demonstrated an average increase of $4.2 \%$ in cortical thickness with $70.4 \%$ of hips showing increased or unchanged cortical thickness. The intramedullary diameter below the tip of the stem demonstrated an average decrease of $1.7 \%$ corresponding with encroachment into the canal from the thickening medial and lateral cortices.

In combining the medial and lateral sides, cumulative changes in cortical thickness for the proximal, middle, distal and stem tip regions were measured for the anteropos- 
Average Change in AP Cortical Thickness

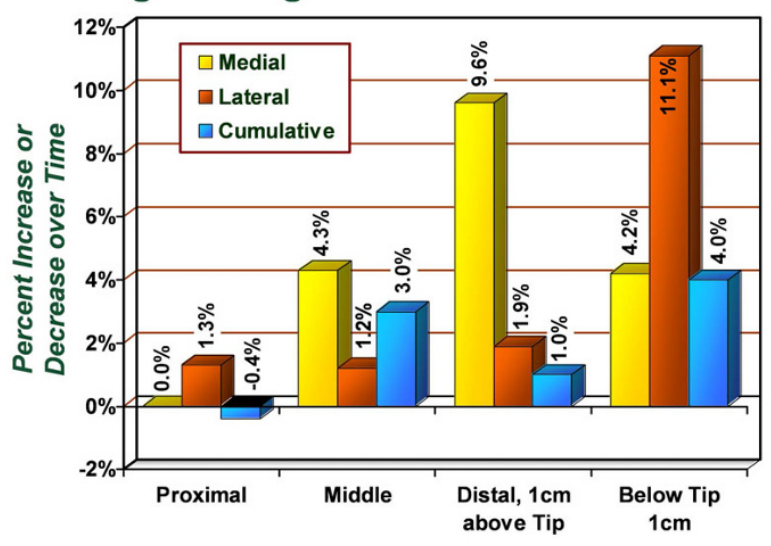

Figure 3

Graph demonstrating the average percentage change in cortical thickness by zone on anteroposterior radiographs, from immediate postoperative to most recent follow-up evaluation.

terior radiographs. In the proximal region, the cumulative cortical thickness decreased $0.4 \%$ with $56.3 \%$ of hips demonstrating increased or unchanged cortical thickness. In the middle region, the cumulative cortical thickness increased $3.0 \%$ with $60 \%$ of hips demonstrating increased or unchanged cortical thickness. In the distal region, the cumulative cortical thickness increased $1.0 \%$ with $64.0 \%$ of hips demonstrating increased or unchanged cortical

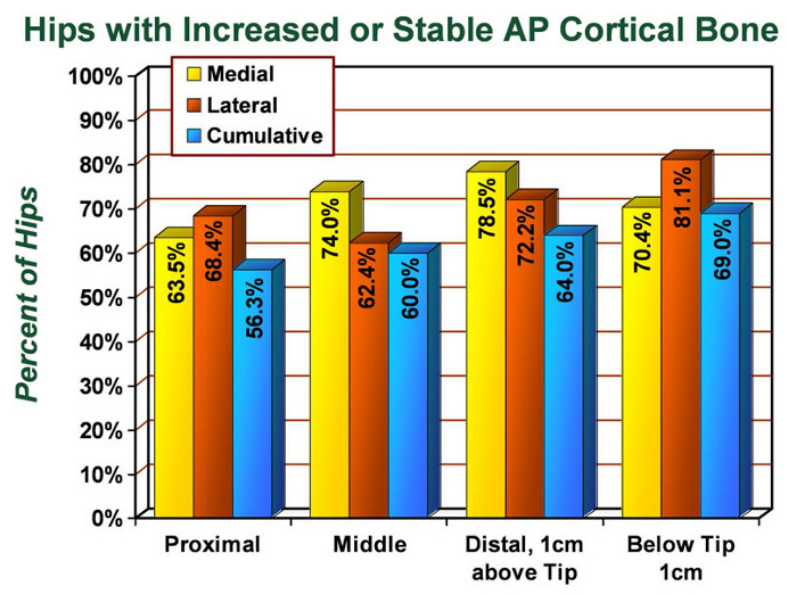

Figure 4

Graph demonstrating the percentage of hips in the series which had stable or increased cortical thickness by zone on anteroposterior radiographs, from immediate postoperative to most recent follow-up evaluation. thickness. At $1 \mathrm{~cm}$ below the stem, the cumulative cortical thickness increased $4.0 \%$ with $69.1 \%$ of hips demonstrating increased or unchanged cortical thickness. No distal osteolysis, progressive radiolucent lines, or signs of loosening were identified on any anteroposterior radiograph.

Similar to the radiographic standardization performed with the picture archiving and communication system technique using the anteroposterior radiographs, similar measurements were made using the lateral radiographs (Figures 5 and 6). In the proximal lateral region (Gruen zone 1 ), an average decrease of $0.98 \%$ in cortical thickness was observed with $77.0 \%$ of hips demonstrating increased or unchanged cortical thickness in this zone. In the proximal medial region (Gruen zone 7), an average increase of $1.5 \%$ was observed with $64.8 \%$ of hips demonstrating increased or unchanged cortical thickness in this zone. In the middle lateral region (Gruen zone 2), an average increase of $1.3 \%$ in the cortical thickness was observed with $65.9 \%$ of hips demonstrating increased or unchanged cortical thickness in this zone. In the middle medial zone (Gruen zone 6), an average increase of $2.4 \%$ in the cortical thickness was observed with $71.4 \%$ of hips demonstrating increased or unchanged cortical thickness. In the distal lateral zone (Gruen zone 3), an average increase of $2.1 \%$ in the cortical thickness was observed with $74.7 \%$ of hips demonstrating increased or unchanged cortical thickness in this zone. In the distal medial zone (Gruen zone 5) the average increase of 3.5\% in the cortical thickness was observed with $70.5 \%$ of subjects demonstrating increased or unchanged cortical thickness. In Gruen zone 4, the average increase in the lateral

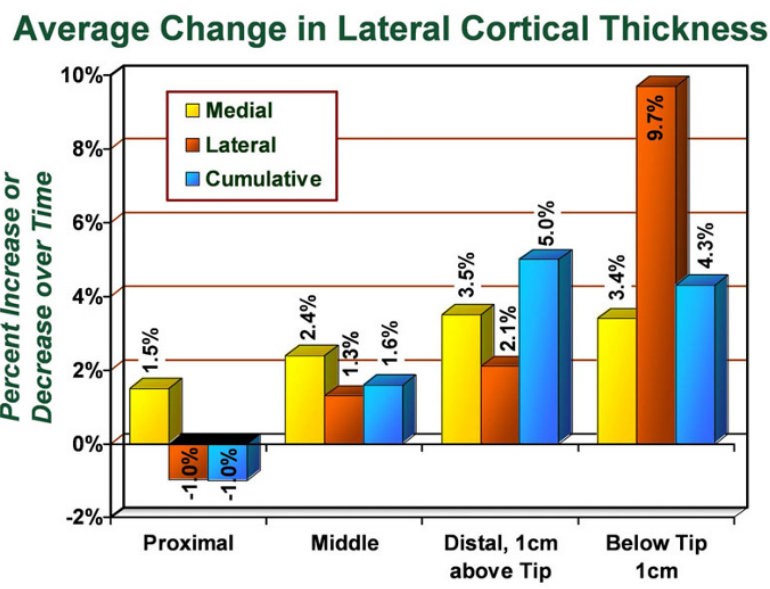

Figure 5

Graph demonstrating the average percentage change in cortical thickness by zone on lateral radiographs, from immediate postoperative to most recent follow-up evaluation. 
Hips with Increased or Stable Lateral Cortical Bone

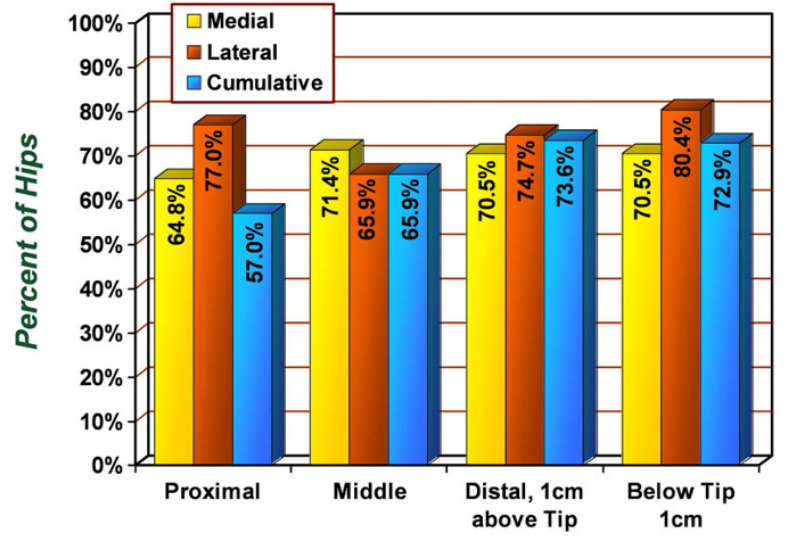

Figure 6

Graph demonstrating the percentage of hips in the series which had stable or increased cortical thickness by zone on lateral radiographs, from immediate postoperative to most recent follow-up evaluation.

cortex was $9.7 \%$ with $80.4 \%$ of hips demonstrating increased or unchanged cortical thickness and the average increase in the medial cortex was. Additionally, the medial cortex in Gruen zone 4 demonstrated an average increase of $3.4 \%$ in cortical thickness with $70.5 \%$ of hips showing increased or unchanged cortical thickness. The intramedullary diameter below the tip of the stem demonstrated an average decrease of $0.9 \%$ corresponding with encroachment into the canal from the thickening medial and lateral cortices.

In combining the medial and lateral sides, cumulative changes in cortical thickness for the proximal, middle, distal and stem tip regions were measured for the lateral radiographs. In the proximal region, the cumulative cortical thickness decreased $1.0 \%$ with $57.0 \%$ of subjects demonstrating increased or unchanged cortical thickness. In the middle region, the cumulative cortical thickness increased $1.6 \%$ with $65.9 \%$ of subjects demonstrating increased or unchanged cortical thickness. In the distal region, the cumulative cortical thickness increased 5.0\% with $73.6 \%$ of subjects demonstrating increased or unchanged cortical thickness. At $1 \mathrm{~cm}$ below the stem, the cumulative cortical thickness increased $4.3 \%$ with $72.9 \%$ of subjects demonstrating increased or unchanged cortical thickness. No distal osteolysis, progressive radiolucent lines, or signs of loosening were identified on any radiograph.

\section{Canal Fill and Cortical Bone Hypertrophy}

Using the anteroposterior and lateral radiographs, measurements were made to determine the percentage of femoral canal filled by the implant stem proximally at the level of the lesser trochanter and also $100 \mathrm{~mm}$ distal to the lesser trochanter. For the anteroposterior radiographs, $81.1 \%$ of the canal was filled at the lesser trochanter, while $84.8 \%$ of the canal was filled $100 \mathrm{~mm}$ distal to the lesser trochanter. Cortical bone hypertrophy around the stem was quantified for each patient throughout the course of their follow-up care using statistical analyses of the radiographic data. No Spearman correlation (r) was observed between cortical bone hypertrophy and canal fit at $100 \mathrm{~mm}$ distal to the lesser trochanter for the proximal, middle, and distal femur using the anteroposterior radiographs $(\mathrm{r}=-0.18,0.05$, and 0.00 , respectively; $\mathrm{p}$ value $=$ $0.09,0.67,0.97$, respectively). For the lateral radiographs, $73.1 \%$ of the canal was filled at the lesser trochanter, while $81.0 \%$ of the canal was filled $100 \mathrm{~mm}$ distal to the lesser trochanter. Unlike the anteroposterior radiograph, the lateral radiograph revealed a significant positive relationship between cortical bone hypertrophy and canal fill at $100 \mathrm{~mm}$ for the proximal, mid-level and distal femur (Spearman correlation, $\mathrm{r}=0.85,0.33$, and 0.28 , respectively; $\mathrm{p}$ value $=0.001,0.016$, and 0.01 , respectively) .

\section{Complications}

In the 97 primary total hip arthroplasty cases of this study, no distal osteolysis was identified. No progressive radiolucent lines or signs of loosening were identified on any radiograph. Two of the primary total hip arthroplasty cases required irrigation and debridement for a wound hematoma in one case and acute infection in another. One revision for aseptic loosening of the stem was performed 13 years following the initial surgery. No cases of stem breakage were identified.

\section{Discussion}

As longevity of cementless femoral components enters the third decade, concerns arise with long-term effects of fixation mode on femoral bone morphology [1-13]. We examined the long-term consequences of the MalloryHead Porous prosthesis, a porous plasma-sprayed, tapered, titanium stem, on cortical remodeling of the proximal femur following primary total hip arthroplasty.

The authors have a more than 20-year experience with the use of the Mallory-Head Porous stem and have demonstrated excellent long-term survivorship in a number of patient populations [16-21]. The titanium substrate of this stem is thought to more closely match the stiffness of the native femur, therein minimizing stress shielding $[3,6,8,9,16-27]$. The tapered geometry facilitates the transfer of strain proximally to the metaphysis, which further reduces the effects of stress shielding [26,27]. Additionally, the circumferential proximal porous coating of the stem encourages stable metaphyseal fixation and securely seals the effective joint space preventing migration of polyethylene wear debris along the stem [28]. In combination, the Mallory-Head Porous prosthesis assimilates key features of successful cementless stem designs, which 
likely explain the outstanding fixation and clinical outcomes observed over long-term follow-up studies [1621,27-33]. Furthermore, the current study provides evidence that the Mallory-Head Porous prosthesis does not cause stress shielding in most patients at an average of 14 year follow-up.

In a related study, Berry et al. examined long-term serial radiographs of 103 hips with either cemented, extensively coated, or proximally coated metaphyseal filling designed anatomic stems [34]. The well-fixed stems with a minimum of 15 to 20 year follow-up were evaluated. Similar to our study, they utilized a standard protocol to measure cortical thickness. Interestingly, Berry et al. reported a time dependent cortical thickness decrease around all stems. This decrease was noted to be most severe with the extensively porous coated stems. They noted a 57\% decrease in cortical thickness around these extensively porous coated cobalt chrome stems. The least amount of cortical thickness lost occurred around well-fixed cemented Charnley-type stems with a $12 \%$ loss. The proximally porous coated anatomic metaphyseal filling stem had a $17 \%$ overall bone loss. In our study, time dependent cortical thickness was either increased or unchanged in the majority of stems. One significant distinction between the study of Berry et al. and the current study is that the Porous Coated Anatomic (Stryker Howmedica, Rutherford, New Jersey) stem, examined as the proximally porous coated uncemented representative type stem, is a bead-coated, anatomic, proximally metaphyseal-filling cobalt-chrome stem, and not a titanium proximally porous-coated tapered design. In the current series with the Mallory-Head Porous plasma spray-coated stem, the tapered design and titanium substrate likely produce a more anatomic offloading of the stresses around the well fixed implant, resulting in an overall positive bony response throughout all of the zones examined.

Similar to the study by Berry et al., the current series was performed using computer measurements of cortical thickness [34]. This is in contrast to several previous studies which have utilized dual energy $\mathrm{x}$-ray absorptiometry or computed tomography to examine bone mineral density changes around femoral stems [1,35-44]. It is believed that dual energy $\mathrm{x}$-ray absorptiometry may be an accurate measure of bone remodeling after total hip arthroplasty. This technique evaluates bone mineral content across the path of the scan. Dual energy x-ray absorptiometry is certainly therefore valuable to monitor change in bone mineral density with time before and following implantation of a total hip replacement. Engh et al. have reported a 45\% decrease in dual energy x-ray absorptiometry bone mineral density in the proximal femur after implantation of a cobalt chrome stem with diaphyseal fixation [35]. Other methods of measuring periprosthetic bone remodeling that have been used include computed tomography scanning. Schmidt et al. examined fifteen hips three years after operation using computed tomography and noted an average overall decrease in bone mineral density of $14.2 \%$ [44]. They noted a cortical bone mineral density decrease of $15.5 \%$ in the metaphyseal region and a corresponding average decrease in bone mineral density of $10 \%$ in the diaphyseal region.

Similar to Berry et al., we have chosen to evaluate radiographic changes in bone stock in this long-term study [34]. The current radiographic evaluation, when calibrated for magnification, showed the majority of proximal femora had a positive bony response throughout the areas exposed to the femoral stem. While dual energy $\mathrm{x}$ ray absorptiometry or computed tomography may be accurate methods of measuring bone mineral content around well-fixed stems, plain radiographs are the standard by which fixation of femoral stems is determined. Additionally, the authors believe that radiographic examination of cortical thickness and proximal femoral bone stock should continue to play a critical role in the evaluation of femoral stem fixation and guide revision surgery, when necessary. Routine radiographic studies can be followed clinically over time when calibrated for magnification by the aforementioned technique. With the use of the Stryker picture archiving and communication system, we were able to accurately and reproducibly measure changes in cortical bone thickness over a 15-year average followup timeframe.

Another important study is that of Maloney et al., who examined cadaveric implant registry specimens to measure the pattern of femoral bone loss and remodeling around both cemented and cementless femoral components [45]. The changes which they examined included cortical bone thickness, cortical bone area, and bone mineral density. In this diverse group of patients, the examiners were unable to statistically correlate the amount of remodeling with either cemented or cementless fixation. In the current study, all patients underwent implantation of an identical femoral stem using an identical surgical technique and surgical approach. This is one of the strengths of the current study. Maloney et al. also noted significant variation in the remodeling response between individuals with both cemented and cementless implants [45]. In the current study we noted a wide range of morphological changes and bony response to the implantation of this proximally porous coated tapered titanium femoral stem. For example, using the anteroposterior radiographic data, the proximal medial region bone loss in one patient was $75 \%$ of the cortical diameter while other patients demonstrated a greater that $50 \%$ increase in cortical diameter in this region. One theory is that this variability in bony response may be related to the amount of 
canal fill obtained with this design. The current authors were able to demonstrate that this canal fill is strongly correlated with positive bony response on the lateral radiograph, representative of the three-point stability obtained with this relatively long titanium stem. Similar findings were identified by Gosens et al., where cortical thickening was observed in stems demonstrating a tight fill, with the greatest increased cortical thickness observed in the middle and distal zones [24]. Conversely, a non-tight fitting stem demonstrated greater spot-welding (cancellous densification) and was less likely to develop cortical thickening.

The current study provides increased information following the work of Berry et al., who concluded that morphologic changes are prominent in the proximal femur following total hip arthroplasty and strongly affected by the type of implant fixation [34]. This tapered titanium proximally porous coated stem does not show the classic signs of radiographic stress shielding that have been described in long-term follow-up of well fixed diaphyseal locking cobalt chrome stems. It should be noted that at this time frame, the majority of patients were young with an average age of only 50 years. This may have significant implications on the long term remodeling around any cementless stem in an older patient. The current authors have, however, shown excellent long-term survivorship with the use of this particular titanium tapered stem in elderly patients, and have not seen any significant problems with negative bony remodeling associated with its use [16].

The current series with long-term follow-up may represent a positive bony remodeling that had previously been predicted by Wixson et al [41]. Again using DEXA they noted a significant positive remodeling 2 years after implantation. Only a $1 \%$ decrease in bone mass was detected compared with nearly $15 \%$ in the early postoperative period. The current authors believe that the titanium femoral component with closed pore proximal porous coating and a long tapered design may offload the femur in a positive way. Therefore, in long-term follow-up, no negative problems are observed.

Potential shortcomings in the study design may include the high number of cases which were excluded for technical reasons. Furthermore, only well-fixed, well-functioning total hip arthroplasties were included. This potential confounding issue is off-set by the excellent long-term survivorship reported with this implant design, implying that few cases were excluded for reasons of early failure. Finally, as discussed the authors used calibrated radiographic measurements, which may have inherent inaccuracies or error. The immediate post-operative and most- recent radiographs were calibrated and measured in identical fashion, potentially reducing any inherent error.

\section{Conclusion}

This femoral stem with its tapered titanium design and circumferential proximal plasma spray porous coating in well-fixed and well-functioning total hip arthroplasty does not cause the classic radiographic signs of stress shielding. Instead, the majority of cases demonstrate increased or unchanged cortical bone thickness in all locations surrounding the femoral stem. This lack of stress shielding is likely a result of the tapered geometry, circumferential proximal porous coating, and the titanium substrate. Continued observation is necessary into the third decade to determine if natural aging of the patient and femur will result in any negative signs of femoral remodeling. The most significant predictor of positive bony remodeling was canal fill on the lateral radiograph, highlighting the importance of surgical technique and relatively long-stem design. The authors continue to use this femoral component with its encouraging long-term clinical outcomes, excellent survivorship in a multitude of patient populations, and the current information showing increased or unchanged cortical bone thickness over time in the majority of cases.

\section{Competing interests}

All research herein was conducted in accordance with ethical standards in compliance with privacy guidelines and in accordance with our institution and independent IRB. All patients have signed a General Research Consent approved by our independent IRB, which allows for their information to be included in our study. All material herein is new and the original work of the authors listed. This manuscript has not been previously published and is not submitted for publication elsewhere. Benefits or funds were received in support of this study from Biomet, Inc. Payments and other benefits were received by me and my co-authors Adolph Lombardi, M.D. and Thomas Mallory, M.D., from Biomet, Inc. In addition, a foundation with which we are affiliated has received payments or other benefits from Biomet, Inc.; Donjoy Orthopaedics, Inc.; Innomed, Inc.; Medtronic; Osteosolutions; Pfizer; Smith \& Nephew; Sofamor Danek, Stryker and Zimmer.

\section{Authors' contributions}

$\mathrm{AVL}, \mathrm{THM}$ and KRB performed the clinical evaluation, surgical treatment and perioperative care for each patient included in the investigation. BSE and NAC conducted the radiographic assessment and data analysis. BSE and KRB participated in the design and coordination of the investigation, and collaborated to draft the manuscript. All authors read and approved the final manuscript. 


\section{Acknowledgements}

The authors would like to acknowledge Joanne Adams for contributions to the medical illustrations displayed in this manuscript. Three authors (AVL, THM, KRB) receive royalties and have consulting agreements with Biomet, Inc. (Warsaw, IN, USA). One author (KRB) has consulting agreements with Synvasive and Salient Surgical. One author (AVL) receives royalties from Innomed, Inc. and is a board member of a foundation that has received support from Allergan, GlaxoSmithKline, Medtronic, Merck, Mount Carmel New Albany Surgical Hospital, and Smith \& Nephew.

\section{References}

I. Aldinger PR, Sabo D, Pritsch M, Thomsen M, Mau H, Ewerbeck V Breusch SJ: Pattern of periprosthetic bone remodeling around stable uncemented tapered stems: a prospective 84-month follow-up study and a median I56-month cross-sectional study with DXA. Calcif Tissue Int 2003, 73(2): I I5-I2I.

2. Crowninshield RD, Maloney WJ, Wentz DH, Levine DL: The role of proximal femoral support in stress development within hip prostheses. Clin Orthop Relat Res 2004, 420: I76-180.

3. Emerson RH Jr: Proximal ingrowth components. Clin Orthop Relat Res 2004, 420: I30-I 34.

4. Engh CA, Massin P, Suthers KE: Roentgenographic assessment of the biologic fixation of porous-surfaced femoral components. Clin Orthop Relat Res 1990, 257:107-128.

5. Engh CA, O'Connor D, Jasty M, McGovern TF, Bobyn JD, Harris WH: Quantification of implant micromotion, strain shielding, and bone resorption with porous-coated anatomic medullary locking femoral prostheses. Clin Orthop Relat Res 1992, 285: 13-29.

6. Rubash HE, Sinha RK, Shanbhag AS, Kim SY: Pathogenesis of bone loss after total hip arthroplasty. Orthop Clin North Am 1998, 29(2): $173-186$.

7. Engh CA Jr, Young AM, Engh CA Sr, Hopper RH Jr: Clinical consequences of stress shielding after porous-coated total hip arthroplasty. Clin Orthop Relat Res 2003, 417:157-I63.

8. Head WC, Bauk DJ, Emerson RH Jr: Titanium as the material of choice for cementless femoral components in total hip arthroplasty. Clin Orthop Relat Res 1995, 3 I I:85-90.

9. Hofmann AA, Feign ME, Klauser W, VanGorp CC, Camargo MP: Cementless primary total hip arthroplasty with a tapered, proximally, porous-coated titanium prosthesis. A 4- to 8year retrospective review. J Arthroplasty 2000, I 5:833-839.

10. Bourne RB, Rorabeck CH, Ghazal ME, Lee MH: Pain in the thigh following total hip replacement with a porous-coated anatomic prosthesis for osteoarthrosis. A five-year follow-up study. J Bone Joint Surg Am 1994, 76( I 0): | 464- I470.

II. Engh CA Jr, Claus AM, Hopper RH Jr, Engh CA: Long-term results using the anatomic medullary locking hip prosthesis. Clin Orthop Relat Res 200I, 393:137-I46.

12. Götze C, Tschungunow A, Götze HG, Böttner F, Pötzl W, Gosheger G: Long-term results of the metal-cancellous Lübeck total hip arthroplasty: a critical review at $\mathbf{1} 2.8$ years. Arch Orthop Trauma Surg 2006, I 26(I):28-35.

13. Hallan G, Lie SA, Havelin LI: High wear rates and extensive osteolysis in 3 types of uncemented total hip arthroplasty: a review of the PCA, the Harris Galante and the Profile/TriLock Plus arthroplasties with a minimum of I 2 years median follow-up in 96 hips. Acta Orthop 2006, 77(4):575-584.

14. Gruen TA, McNiece GM, Amstutz HC: "Modes of failure" of cemented stem-type femoral components: a radiographic analysis of loosening. Clin Orthop Relat Res 1979, I41:17-27.

15. Frndak PA, Mallory TH, Lombardi AV Jr: Translateral surgical approach to the hip. The abductor muscle "split". Clin Orthop Relat Res 1993, 295:135-141.

16. Berend KR, Lombardi AV Jr, Mallory TH, Dodds KL, Adams JB: Cementless double-tapered arthroplasty in patients 75 years of age and older. I Arthroplasty 2004, I 9(3):288-295.

17. Berend KR, Lombardi AV Jr, Mallory TH, Dodds KL, Adams JB: Cerclage wires or cables for the management of intraoperative fracture associated with a cementless tapered femoral prosthesis: Results at 2-16 years. J Arthroplasty 2004, I9(7 Suppl 2): $|7-2|$.

18. Berend KR, Mallory TH, Lombardi AV Jr, Dodds KL, Adams JB: Tapered cementless femoral stem: difficult to place in varus but performs well in those rare cases. Orthopedics 2007 , 30(4):295-297.

19. Ellison B, Berend KR, Lombardi AV Jr, Mallory TH: Tapered titanium porous plasma-sprayed femoral component in patients aged 40 years and younger. J Arthroplasty 2006, 2 I (6 Suppl 2):32-37.

20. Lombardi AV Jr, Berend KR, Mallory TH: Hydroxyapatite-coated titanium porous plasma spray tapered stem: Experience at I 5 - I 8 years. Clin Orthop Relat Res 2006, 453:8I-85.

21. Mallory TH, Lombardi AV Jr, Leith JR, Fujita H, Hartman JF, Capps SG, Kefauver CA, Adams JB, Vorys GC: Minimal I0-year results of a tapered cementless femoral component in total hip arthroplasty. J Arthroplasty 200I, I 6(8 suppl I):49-54.

22. Bourne RB, Rorabeck CH: Porous coated femoral fixation: the long and short of it! Orthopedics 2003, 26(9):9|।-912.

23. Gillies RM, Morberg PH, Bruce WJ, Turnbull A, Walsh WR: The influence of design parameters on cortical strain distribution of a cementless titanium femoral stem. Med Eng Phys 2002, 24(2): $109-1 \mid 4$.

24. Gosens T, Sluimer JC, Kester AD, van Langlaan EJ: Femoral fit predicts radiologica changes, but not clinical results in MalloryHead total hip arthroplasties. Clin Orthop Relat Res 2005, 432:138-147.

25. Head WC, Mallory TH, Emerson RH Jr: The proximal porous coating alternative for primary total hip arthroplasty. Orthopedics 1999, 22(9):8|3-8|5.

26. Hozack WJ, Rothman RH, Eng K, Mesa J: Primary cementless hip arthroplasty with a titanium plasma sprayed prosthesis. Clin Orthop Relat Res 1996, 333:217-225.

27. Mallory TH, Head WC, Lombardi AV Jr: Tapered design for the cementless total hip arthroplasty femoral component. Clin Orthop Relat Res 1997, 344: I72-I78.

28. Emerson RH Jr, Sanders SB, Head WC, Higgins L: Effect of circumferential plasma-spray porous coating on the rate of femoral osteolysis after total hip arthroplasty. J Bone Joint Surg Am I999, 8I(9): | 29|-1298.

29. Bourne RB, Rorabeck CH, Patterson JJ, Guerin J: Tapered titanium cementless total hip replacements: a I 0- to I3-year followup study. Clin Orthop Relat Res 2001, 303: I I2-120.

30. Emerson RH Jr, Head WC, Emerson CB, Rosenfeldt W, Higgins LL: A comparison of cemented and uncemented titanium femoral components used for primary total hip arthroplasty: a radiographic and survivorship study. J Arthroplasty 2002, I 7(5):584-59|.

31. Gosens T, van Langelaan EJ, Tonino AJ: Cementless Mallory-Head HA-coated hip arthroplasty for osteoarthritis in hip dysplasia. J Arthroplasty 2003, I 8(4):401-410.

32. Park MS, Choi BW, Kim SJ, Park JH: Plasma spray-coated Ti femoral component for cementless total hip arthroplasty. J Arthroplasty 2003, I 8(5):626-630.

33. Reitman RD, Emerson R, Higgins L, Head W: Thirteen year results of total hip arthroplasty using a tapered titanium femoral component inserted without cement in patients with type $\mathbf{C}$ bone. J Arthroplasty 2003, I 8(7 Suppl I): I | 6- I 2 |

34. Berry DJ, Collins DC, Harmsen W, Xenos JS, Callaghan JJ, Engh CA Ir, Engh CA Sr: How does prosthesis fixation type alter long. term femoral cortical bone remodeling around THA? Presented as Poster 005 at the American Academy of Orthopedic Surgeons 2005 Annual Meeting, Washington, DC, February 23-27, 2005

35. Engh CA, McGovern TF, Bobyn JD, Harris WH: A quantitative evaluation of periprosthetic bone-remodeling after cementless total hip arthroplasty. J Bone Joint Surg Am 1992, 74(7): 1009-1020.

36. Gibbons CE, Davies AJ, Amis AA, Olearnik H, Parker BC, Scott JE: Periprosthetic bone mineral density changes with femoral components of differing design philosophy. Int Orthop 2001, 25(2):89-92.

37. Grant $P$, Aamodt A, Falch JA, Nordsletten L: Differences in stability and bone remodeling between a customized uncemented hydroxyapatite coated and a standard cemented femoral stem. A randomized study with use of radiostereometry and bone densitometry. J Orthop Res 2005, 23(6): I 280-I285.

38. Kiratli BJ, Checovich MM, McBeath AA, Wilson MA, Heiner JP: Measurement of bone mineral density by dual-energy x-ray absorptiometry in patients with the Wisconsin hip, an uncemented femoral stem. J Arthroplasty 1996, I I (2): I84-I93. 
39. Kiratli BJ, Heiner JP, McBeath AA, Wilson MA: Determination of bone mineral density by dual $x$-ray absorptiometry in patients with uncemented total hip arthroplasty. J Orthop Res 1992, 10(6):836-844.

40. Kröger H, Venesmaa P, Jurvelin J, Miettinen H, Suomalainen O, Alhava E: Bone density at the proximal femur after total hip arthroplasty. Clin Orthop Relat Res 1998, 352:66-74.

41. Wixson RL, Stulberg SD, Van Flandern GJ, Puri L: Maintenance of proximal bone mass with an uncemented femoral stem analysis with dual-energy-xray-absorptiometry. J Arthroplasty 1997, I 2(4):365-372.

42. Lengsfeld M, Burchard R, Günther D, Pressel T, Schmitt J, Leppek R, Griss P: Femoral strain changes after total hip arthroplasty patient-specific finite element analysis 12 years after operation. Med Eng Phys 2005, 27(8):649-654.

43. Lengsfeld M, Günther D, Pressel T, Leppek R, Schmitt J, Griss P: Validation data for periprosthetic bone remodeling theories. J Biomech 2002, 35( ( 2): I553-1564.

44. Schmidt R, Mueller L, Nowak TE, Pitto RP: Clinical outcome and periprosthetic bone remodeling of an uncemented femoral component with taper design. Int Orthop 2003, 27(4):204-207.

45. Maloney WJ, Sychterz C, Bragdon C, McGovern T, Jasty M, Engh CA, Harris WH: The Otto Aufranc Award. Skeletal response to well fixed femoral components inserted with and without cement. Clin Orthop Relat Res 1996, 333:15-26.

Publish with Biomed Central and every scientist can read your work free of charge

"BioMed Central will be the most significant development for disseminating the results of biomedical research in our lifetime. "

Sir Paul Nurse, Cancer Research UK

Your research papers will be:

- available free of charge to the entire biomedical community

- peer reviewed and published immediately upon acceptance

- cited in PubMed and archived on PubMed Central

- yours - you keep the copyright

Submit your manuscript here:

http://www.biomedcentral.com/info/publishing_adv.asp
BioMedcentral 